\title{
Rates, risk factors $\&$ methods of self harm among minority ethnic groups in the UK: a systematic review Kamaldeep Bhui*1,2, Kwame McKenzie ${ }^{3,4}$ and Farhat Rasul ${ }^{1}$
}

\author{
Address: ${ }^{1}$ Centre for Psychiatry, Barts and The London, Queen Mary's School of Medicine and Dentistry, Old Anatomy Building, Charterhouse \\ Square, London EC1M 6BQ, UK, ${ }^{2}$ East London \& City Mental Health Trust, London, UK, ${ }^{3}$ Centre for Addictions and Mental Health, Toronto \\ University, Toronto, Canada and ${ }^{4}$ University College London, London, UK \\ Email: Kamaldeep Bhui* - k.s.bhui@qmul.ac.uk; Kwame McKenzie - kwame_mckenzie@camh.net; Farhat Rasul - FRasul@uk.imshealth.com \\ * Corresponding author
}

Published: 19 November 2007

BMC Public Health 2007, 7:336 doi:10.1 186/147|-2458-7-336

This article is available from: http://www.biomedcentral.com/147/-2458/7/336

(c) 2007 Bhui et al; licensee BioMed Central Ltd.

This is an Open Access article distributed under the terms of the Creative Commons Attribution License (http://creativecommons.org/licenses/by/2.0), which permits unrestricted use, distribution, and reproduction in any medium, provided the original work is properly cited.
Received: 13 April 2007
Accepted: 19 November 2007

\begin{abstract}
Background: Studies suggest that the rates of self harm vary by ethnic group, but the evidence for variation in risk factors has not been synthesised to inform preventive initiatives.

Methods: We undertook a systematic literature review of research about self harm that compared at least two ethnic groups in the United Kingdom.

Results: 25 publications from 1765 titles and abstracts met our inclusion criteria. There was higher rate of self harm among South Asian women, compared with South Asian men and White women. In a pooled estimate from two studies, compared to their white counterparts, Asian women were more likely to self harm (Relative Risk I.4, 95\%Cl: I.I to I.8, $p=0.005$ ), and Asian men were less likely to self harm (RR 0.5, $95 \% \mathrm{Cl}: 0.4$ to $0.7, \mathrm{p}<0.00 \mathrm{I}$ ). Some studies concluded that South Asian adults self-harm impulsively in response to life events rather than in association with a psychiatric illness. Studies of adolescents showed similar methods of self harm and interpersonal disputes with parents and friends across ethnic groups. There were few studies of people of Caribbean, African and other minority ethnic groups, few studies took a population based and prospective design and few investigated self harm among prisoners, asylum seekers and refugees.
\end{abstract}

Conclusion: This review finds some ethnic differences in the nature and presentation of self harm. This argues for ethnic specific preventive actions. However, the literature does not comprehensively cover the UK's diverse ethnic groups.

\section{Background}

Non-fatal self harm (SH) is common [1]. It places significant burden on care services. The degree of suicidal intent is often difficult to assess, but $\mathrm{SH}$ is the most important risk factor for later completed suicide $[2,3]$ and future selfharm [4]. Mental distress and illness are both risk factors for suicide and self harm. Though there are many studies that show ethnic variations in prevalence of mental ill- ness, and access to care and treatment [5], few have considered the cultural epidemiology of self harm.

Cross cultural investigations of self harm and suicide are necessary to inform future preventive initiatives if these are to be effective across diverse ethnic groups $[6,7]$. Cultural influences are proposed to explain some of the ethnic variations in rates and methods of self harm within any one country and across countries [8-10]. In addition, 
factors known to increase the risk of mental distress, social exclusion, unemployment, and financial strain are more common in some ethnic groups and may increase the risk of self harm among these ethnic groups $[11,12]$.

Clinical assessment and preventive policies rarely take into consideration potentially distinct needs of specific ethnic groups. This partly reflects that the evidence base is not accessible or synthesised to guide practitioners or policy makers to consider ethnic differences in rates and risk factors. This paper reports the findings of a systematic review of UK studies investigating self harm amongst at least two minority ethnic groups. The aim of the review was to establish whether there were ethnic differences in prevalence rates, clinical presentations including risk factors, and methods of self harm across the largest minority ethnic groups in the UK. We hypothesised that prevalence, risk and methods of self harm would differ between South Asian, Black Caribbean, and White British people.

\section{Methods}

The literature review is part of a larger mixed-methods study investigating suicide and self harm in minority ethnic groups commissioned by the National Institute of Mental Health England and the Department of Health's 'Delivering Race Equality' strategy. The paper presents a review of self harm only, but because many studies investigate self harm and suicide, our search strategy targetted both publications on suicide and self harm. Specifically, we searched for publications that included data on a) self harm or suicide, b) in at least two ethnic groups living in the UK, and c) that were published in English. Titles and abstracts of these studies were screened (FR, KB, KM). Full text papers were obtained if from the abstracts the studies were confirmed to a) compare rates or clinical risk factors or methods of self harm or suicide; b) include data on 2 or more ethnic groups living in the UK; c) studies were published in English between 1960 and the start date of the project, 2004. Where there was uncertainty, the full text paper was retrieved. The following databases: MEDLINE, PSYCHINFO, EMBASE and CINAHL. The search strategy used the following search terms: SUICIDE or SUICIDAL IDEATION, or SUICIDAL THOUGHTS, or SUICIDE BEHAVIOUR or SELF-HARM or DELIBERATE SELF-HARM. The strategy was devised with the assistance of a librarian familiar with the databases and MESH terms needed to optimise the search. The findings from this search were combined with a search on ETHNICITY or ETHNIC or RACE. There were 1765 hits. In this paper we review the 25 studies that met our inclusion criteria (see Figure 1).

Two reviewers (KB KM) independently assessed the methodological quality of the studies using a scoring scheme adapted from previous reviews (adapted from [5]; Table
1). Data were extracted and tabulated independently by the two reviewers who tabulated study characteristics (Table 2), clinical risk factors for self harm and methods of self harm (Additional file 1) and prevalence or rates of self harm (Table 3). Adolescent studies were separately reported given the distinct risk of mental health problems, service use and developmental challenges for adolescents.

The largest ethnic minority groups living in the UK are migrants and their descendents from the Indian sub-continent, often called South Asians in the UK. Other migrants and their descendents are from the Caribbean and Africa; these ethnic groups are often called Black Caribbean or African Caribbean if of Caribbean origin and Black African if of African origin. These categories are those used in the 2001 census in the UK. As much as possible we have tried to group different studies together by ethnic minority groups used in the 2001 UK census; but we have retained the group names used by the authors of studies in the tabulated data.

\section{Results}

\section{Methodological Quality}

Sixteen studies obtained a low score (3 or less) on our quality assessment. Seven scored between 4 and 6 (medium score), and two studies scored over 7. Most of the studies scored less than five on quality as they had broad definitions of ethnicity, and adjusted only for age and sex [e.g. [13-15]], or only presented rates of deliberate self harm and poisoning without a detailed assessment of risk factors across ethnic groups [16-22]. Six of the studies recruited adolescents $[16,18,19,21,23,24]$; two of these scored between 4 and $6[19,21]$.

Seventeen studies adopted ethnic group comparisons using a cross-sectional case series. There was one prospective study of people who had a severe mental illness; they were followed up over four years to assess baseline predictors for future outcomes. There were two population studies [19,25]. Three studies used regression analyses, adjusting for confounders [24,26,27]; one study used age standardization [28], otherwise most studies used age/ gender stratification to report rates or presented descriptive data. Half of the studies had less than 30 subjects in all the groups that were compared. Fifteen studies used case notes and other routine sources of data, with the remaining 9 including some interview data, with one using a self report questionnaire [19]. Only four studies used specific instruments to confirm self-harm $[17,21,27,29]$, whereas most studies relied on 'reasons for admission or contact with services' as recorded in the case notes or reported at interview. Hawton et al took special precautions and used three raters to independently validate self harm against an agreed definition [19]. Seven studies included a rate calculation $[12-14,17,20,24,30]$. 


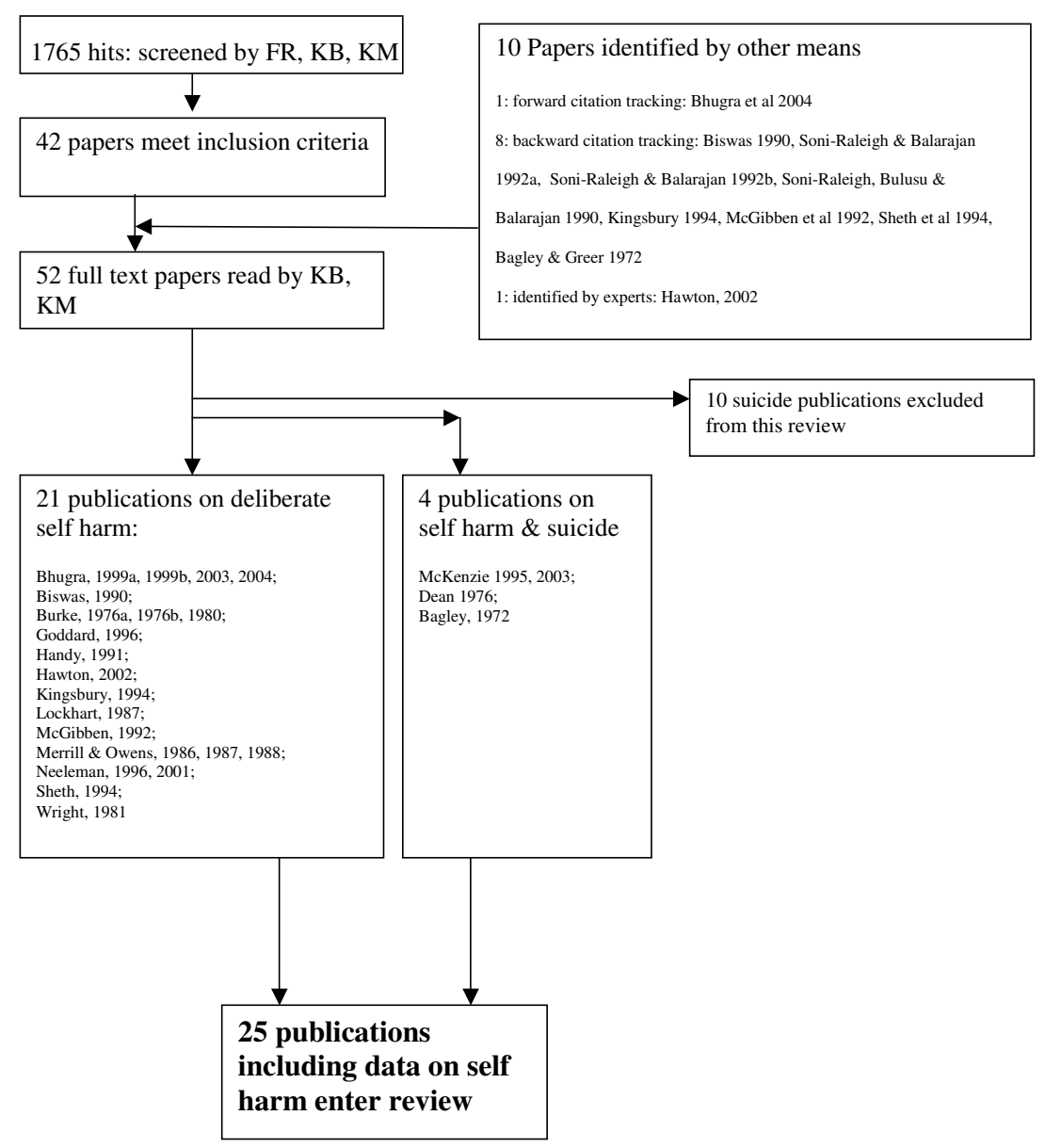

Figure I

Flow chart of identified papers.

Comparison of studies was complicated by the use of different ethnic identifiers. Some studies used self-assigned ethnicity [e.g. [31]], others observer assigned ethnicity and others used place of birth. Ethnic identifiers have changed over time as have ethnic minority groups. Early studies of South Asian groups in the 1970s would be reporting about a group which was predominantly not born in the UK, whereas currently $50 \%$ of the England and Wales South Asian origin population was born in the UK. Early studies, for example those of Burke [12,32,33], used the term "West Indian" which is now not commonly used.

Table I: Paper quality scoring system on five criteria:

\begin{tabular}{|c|c|c|}
\hline I & Size of the study population of relevance & Range 0-I \\
\hline 2 & Power calculation: whether performed or not & Range 0-I \\
\hline 3 & Confounding: degree of adjustment for obvious confounders & $\begin{array}{l}\text { Range } 0 \text {, none; I, age/gender; } 2 \text {, age/gender and socio-economic } \\
\text { indicators }\end{array}$ \\
\hline 4 & Ethnicity definition: whether explicit, accurate and hypothesis based & $\begin{array}{l}\text { Range } 0 \text {, none; } 1 \text {, a definition; } 2 \text {, self assigned; } 3 \text { rated on basis of } \\
\text { self identification and parental origins }\end{array}$ \\
\hline 5 & $\begin{array}{l}\text { Deliberate self harm: whether attempts had been made to ensure the } \\
\text { episode was an actual self harm }\end{array}$ & $\begin{array}{l}\text { Range } 0 \text {, none; I self report; } 2 \text {, some attempt at measurement; } 3 \text {, } \\
\text { well defined and measured }\end{array}$ \\
\hline
\end{tabular}

The maximum possible score was 10 . This schema was piloted to ensure that it discriminated adequately between the papers included. How well a study measured deliberate self harm and how accurately it measured ethnicity were weighted more highly than other criteria because they were considered particularly important for this review 
Table 2: Characteristics of studies on self harm in ethnic groups in the UK

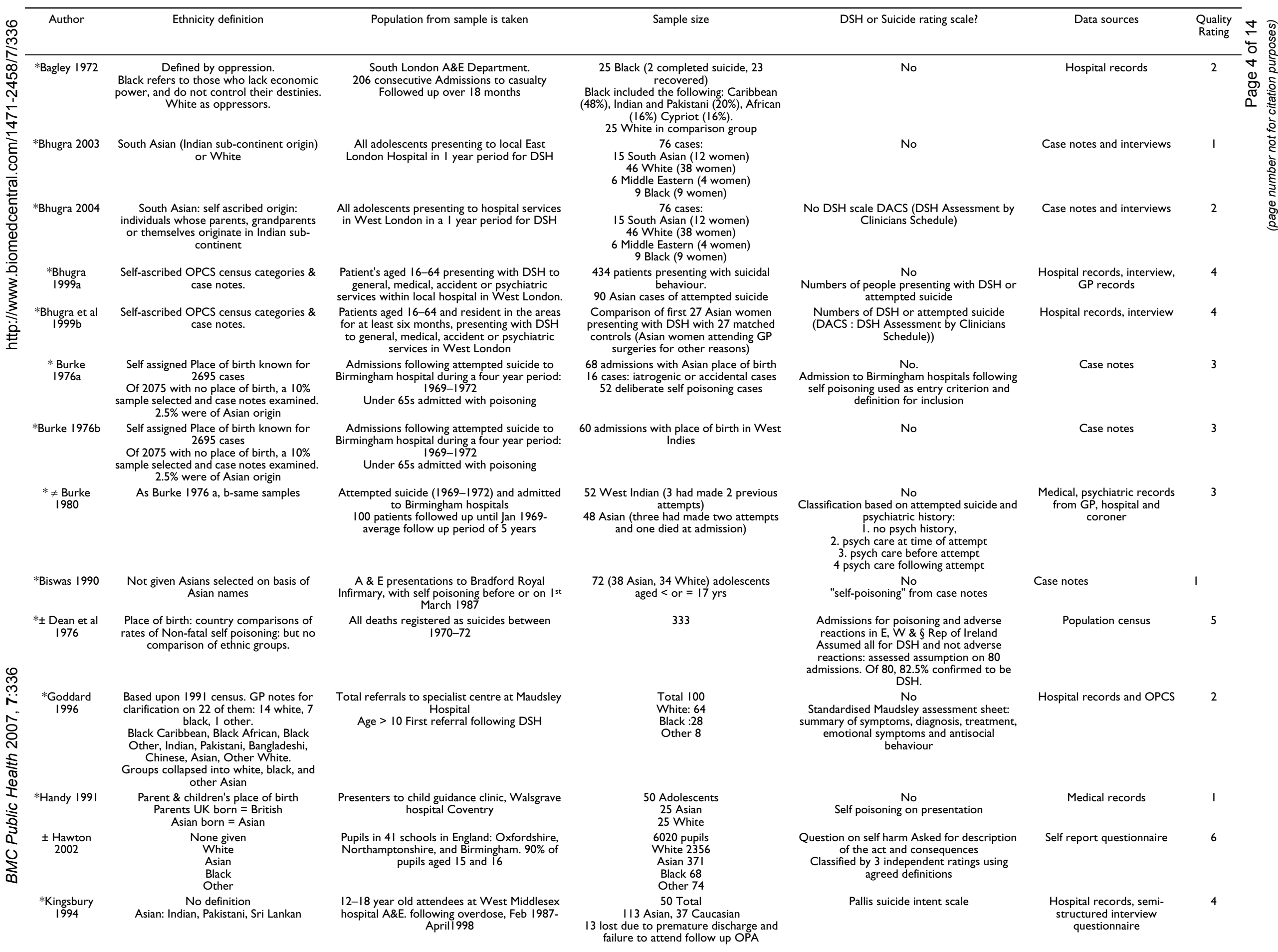


Table 2: Characteristics of studies on self harm in ethnic groups in the UK (Continued)

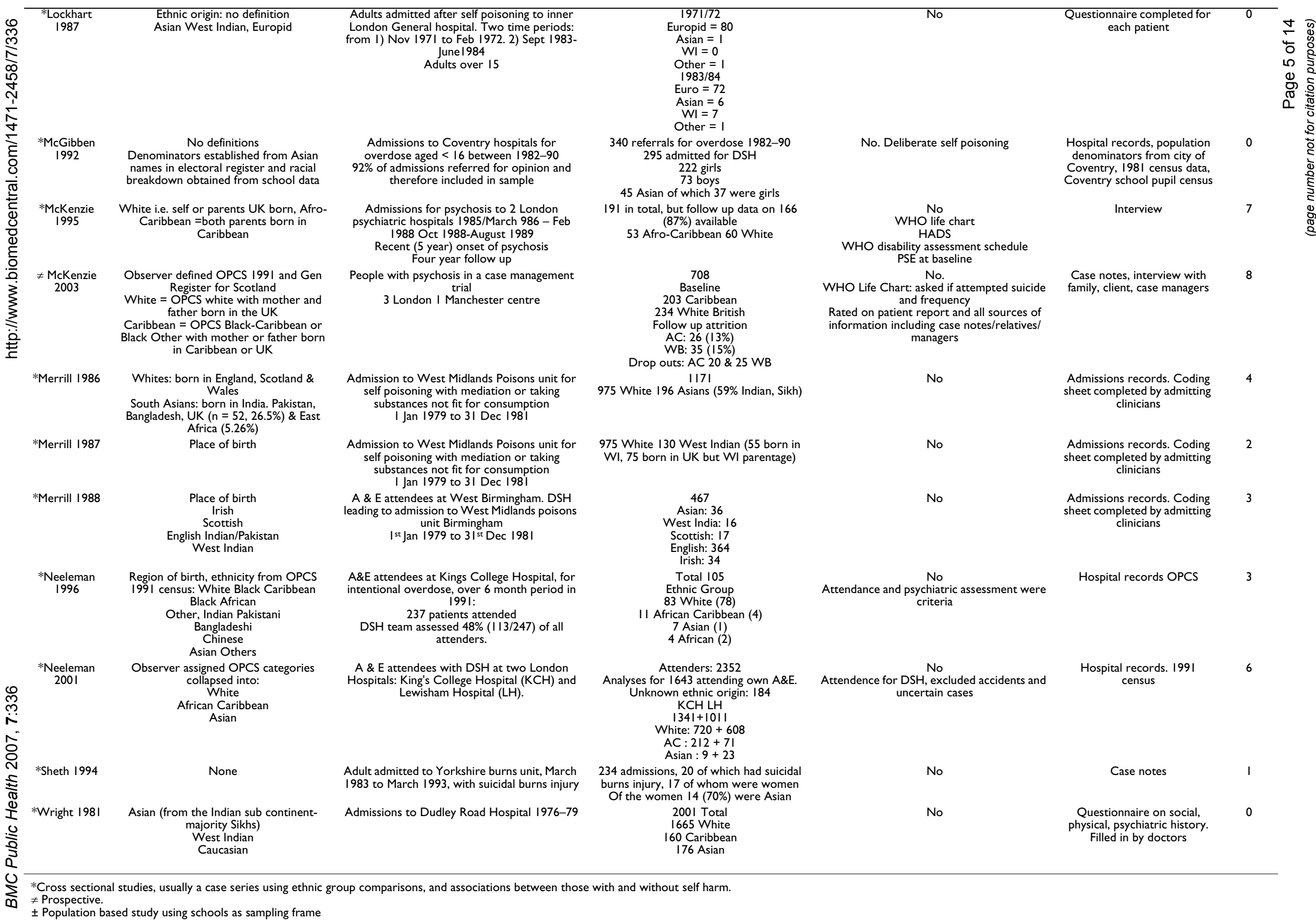


Table 3: Rates of Self Harm across Ethnic groups in the UK

\begin{tabular}{llllll} 
& & & \\
\hline
\end{tabular}

Attempted suicide rates highest in South Asian women aged 16-24 (92.7/10000 person years), aged 25-34 (34.4) and also high in "other" ethnic women aged 16-24 (75.9 per 100000 person years) and aged 25-34 (4I.I).

White men also had high rates compared with other ethnic groups in 16-24 (30.2), 25-34 (28.I), 35-44 (30.I), as did black men in 25-34 age group (3I.8).

Burke Per 100000 South Asian Age

1976a population Adults

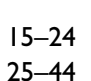

Female Rate

otal Rate

$\begin{array}{llll}15-24 & 213 & 74 & 123 \\ 25-44 & 95 & 70 & 66 \\ 45-64 & 32 & 0 & 9 \\ & 216 & 57 & 79\end{array}$

Rate lower than native population $(57 / 100,000,126 / 100,000)$.

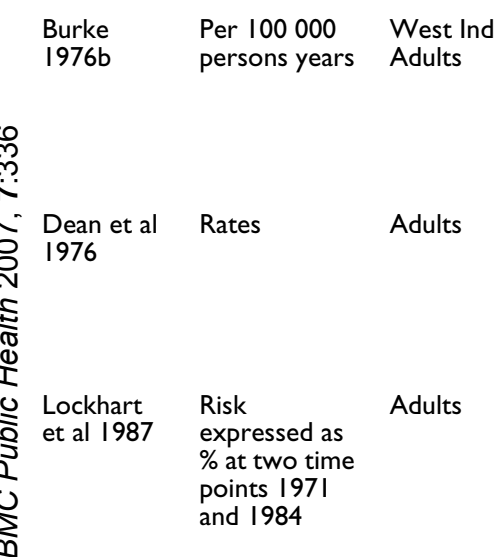

\begin{tabular}{|c|c|c|c|}
\hline Age & Female & Male & Tota \\
\hline $15-24$ & 514 & 101 & 336 \\
\hline $25-44$ & 84 & 66 & 74 \\
\hline Total & 180 & 56 & 113 \\
\hline
\end{tabular}

Rates increasing in all countries, especially in 15-44 age groups, especially among women.

Rates among women in England and Wales are twice the rate for Scotland and Ireland, and four times the rate for Republic of Ireland.

1971: 93 patients admitted on 100 occasions from population of 92720

Summary of Main Findings

Young South Asian women are

vulnerable to increased rates of DSH.

Attempted suicide rates highest in

South Asian women than other ethnic groups but highest in white men, maybe because inclusion of Irish in white category.

In men highest rate in Whites aged 16-24 and Black people aged 25-34.

Proportion of South Asians in self harm group was $60 \%$ of those expected considering population distributions

Women more common among $15-24$ group and men more common at later

Rates among Caribbean females aged 15-24 twice that of males same age.

Low risk of attempted suicide in Caribbean people

Country comparison of rates, England \& Wales rate is greater than those of

An increase in admissions for among West Indians for self-poisoning. 
co Table 3: Rates of Self Harm across Ethnic groups in the UK (Continued)

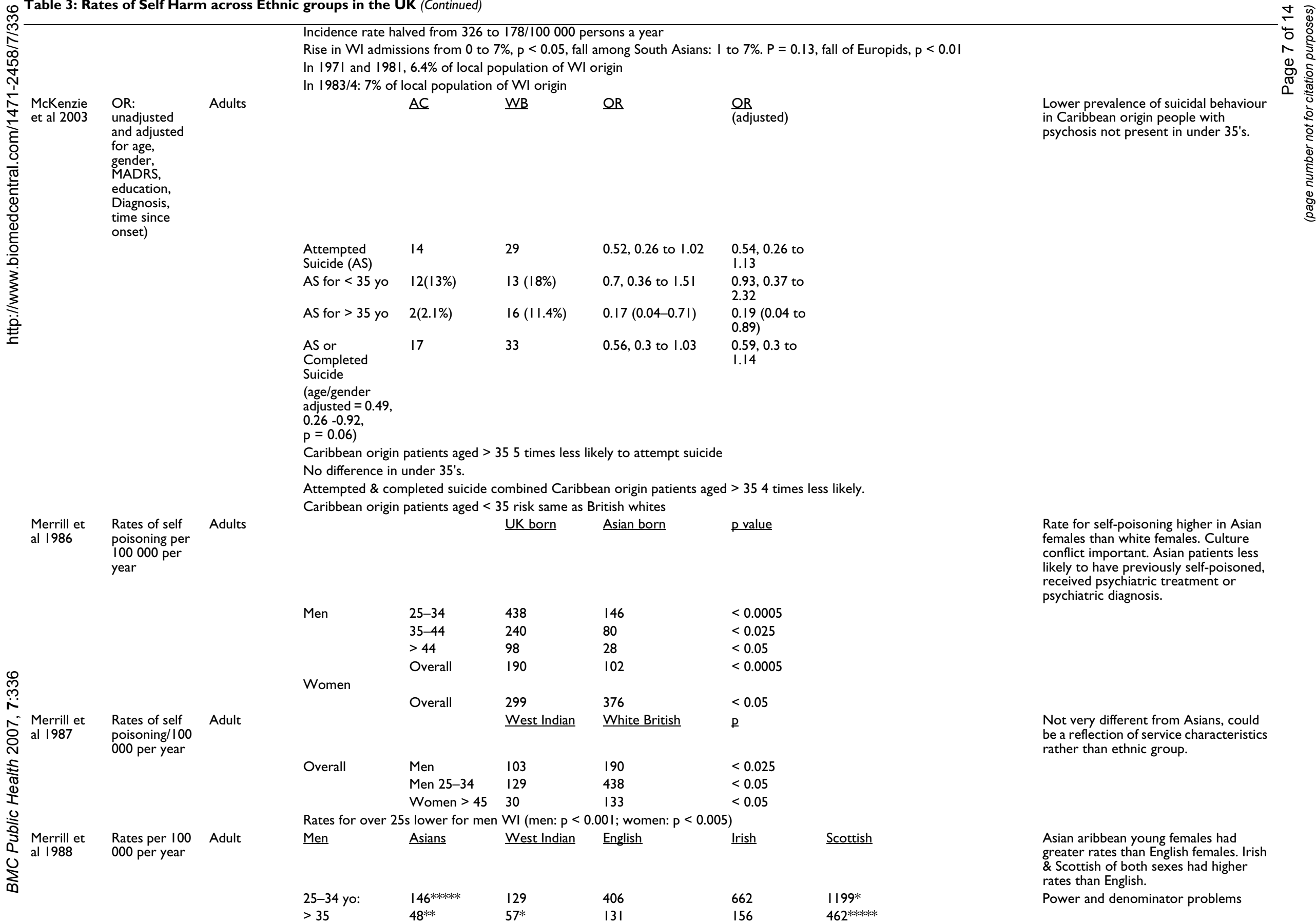


Table 3: Rates of Self Harm across Ethnic groups in the UK (Continued)

\begin{tabular}{|c|c|c|c|c|c|c|c|c|c|c|c|c|}
\hline & & & $<16$ & $113^{* * * * *}$ & $98^{* * *}$ & 236 & 243 & \multirow{2}{*}{\multicolumn{5}{|c|}{$648^{* * * * * * *}$}} \\
\hline & & & Women & & & & & & & & & \\
\hline & & & 25-34 уо: & 501 & 257 & 447 & $853^{*}$ & \multicolumn{5}{|c|}{$565 * * * *$} \\
\hline & & & $>35$ & 90 & 37 & 167 & $367 * * * * * *$ & \multicolumn{5}{|c|}{$547 * * * *$} \\
\hline & & & \multicolumn{10}{|c|}{$*_{\mathrm{p}}<0.05, * * \mathrm{p}<0.01 * * * \mathrm{p}<0.005 * * * * \mathrm{p}<0.001 * * * * * \mathrm{p}<0.0005$} \\
\hline $\begin{array}{l}\text { Neeleman } \\
\text { et al } 1996\end{array}$ & $\begin{array}{l}\text { Referral } \\
\text { Ratios }\end{array}$ & Adult & \multicolumn{9}{|c|}{ Unadjusted Referral Ratios (Ethnic groups generally younger) for all subjects } & $\begin{array}{l}\text { Indian female rates of Self Harm are } 2.6 \\
\text { times the rate of white women }\end{array}$ \\
\hline & & & & Men & Women & All & & & & & & \multirow[t]{5}{*}{$\begin{array}{l}\text { UK born Indian females had } 7.8 \text { times } \\
\text { rate of UK born white females. } \\
\text { Unemployment associated with a 9-fold } \\
\text { increase in referral rates in whites and } \\
\text { 3-fold increase in minorities. }\end{array}$} \\
\hline & & & $\begin{array}{l}\text { Black } \\
\text { Caribbean }\end{array}$ & $\begin{array}{l}0.56 \\
0.16-1.43\end{array}$ & $\begin{array}{l}0.61 \\
0.24-1.26\end{array}$ & $0.61,0.3-1.09$ & & & & & & \\
\hline & & & South Asian & $\begin{array}{l}0.39 \\
0.01-2.17\end{array}$ & $\begin{array}{l}1.68 \\
0.61-3.66\end{array}$ & I.15,0.46-2.37 & & & & & & \\
\hline & & & Indian & 0 & $2.6,0.53-7.6$ & & & & & & & \\
\hline & & & $\begin{array}{l}\text { All Ethnic } \\
\text { groups }\end{array}$ & $\begin{array}{l}0.45 \\
0.17-0.98\end{array}$ & $\begin{array}{l}0.78 \\
0.45-1.27\end{array}$ & $0.65,0.41-0.99$ & & & & & & \\
\hline & & & \multicolumn{10}{|c|}{ Unadjusted Referral Ratios (Ethnic groups generally younger) for UK born only } \\
\hline & & & $A C$ & $\begin{array}{l}0.19 \\
0.00-1.05\end{array}$ & $\begin{array}{l}0.41 \\
0.08-1.20\end{array}$ & $0.32,0.09-0.82$ & & & & & & \\
\hline & & & AS & $1.2,0.03-6.68$ & $\begin{array}{l}3.53 \\
0.96-9.03\end{array}$ & $2.55,0.83-5.95$ & & & & & & \\
\hline & & & IN & 0 & $\begin{array}{l}7.76 \\
1.6-22.66\end{array}$ & & & & & & & \\
\hline & & & \multicolumn{10}{|c|}{$\begin{array}{l}\text { Cross validation study: ethnicity assigned on basis of name, to check that referral to DSH may be biased by ethnic group } \\
\text { rather than reflect attendance. Only possible for Indian names }\end{array}$} \\
\hline & & & \multicolumn{9}{|c|}{ Attendance ratio Indian Men (indirect standardization): $1.92,0.52-10.24$; Indian women: $3.07,1.4$ to 5.8} & \\
\hline $\begin{array}{l}\text { Wright } \\
1981\end{array}$ & $\begin{array}{l}\text { Annual } \\
\text { increase in \% } \\
\text { admissions }\end{array}$ & Adult & \multirow{2}{*}{\multicolumn{2}{|c|}{$\begin{array}{l}\text { Mean annual } \\
\text { increase \% }\end{array}$}} & \multicolumn{7}{|c|}{$\begin{array}{l}\text { \% born in } \\
\begin{array}{l}\text { country of } \\
\text { origin for } \\
\text { ethnic group }\end{array}\end{array}$} & \multirow[t]{5}{*}{$\begin{array}{l}\text { Self-poisoning is an inarticulate cry for } \\
\text { help or even a cry of frustration. }\end{array}$} \\
\hline & & & & & 1976 & $\underline{1979}$ & & & & & & \\
\hline & & & Caucasian & 9.5 & 100 & 100 & & & & & & \\
\hline & & & West Indian & 31.5 & 69.6 & 48 & & & & & & \\
\hline & & & Asian & 14.5 & 83.9 & 70.3 & & & & & & \\
\hline Studies of & Adolescents & & & & & & & & & & & \\
\hline $\begin{array}{l}\text { Hawton } \\
2002\end{array}$ & Prevalence & Adolescents & Males & & & & & Female & & & & $\begin{array}{l}\text { Lower risk among South Asian females } \\
\text { not sustained in multivariate analyses }\end{array}$ \\
\hline & & & White & 2536 & 3.3 & 1 & & 2727 & 11.6 & I & & \\
\hline & & & Asian & 371 & 2.7 & 0.82 & $0.42-1.58$ & 254 & 6.7 & 0.55 & $\begin{array}{l}0.33-0 \\
.91\end{array}$ & \\
\hline & & & Black & 68 & 0 & - & - & 89 & 6.7 & 0.55 & $\begin{array}{l}0.24-1 \\
.27\end{array}$ & \\
\hline & & & Other & 74 & 6.8 & 2.14 & $0.84-5.85$ & 72 & 13.9 & 1.23 & $\begin{array}{l}0.62-2 \\
.42\end{array}$ & \\
\hline
\end{tabular}


co Table 3: Rates of Self Harm across Ethnic groups in the UK (Continued)

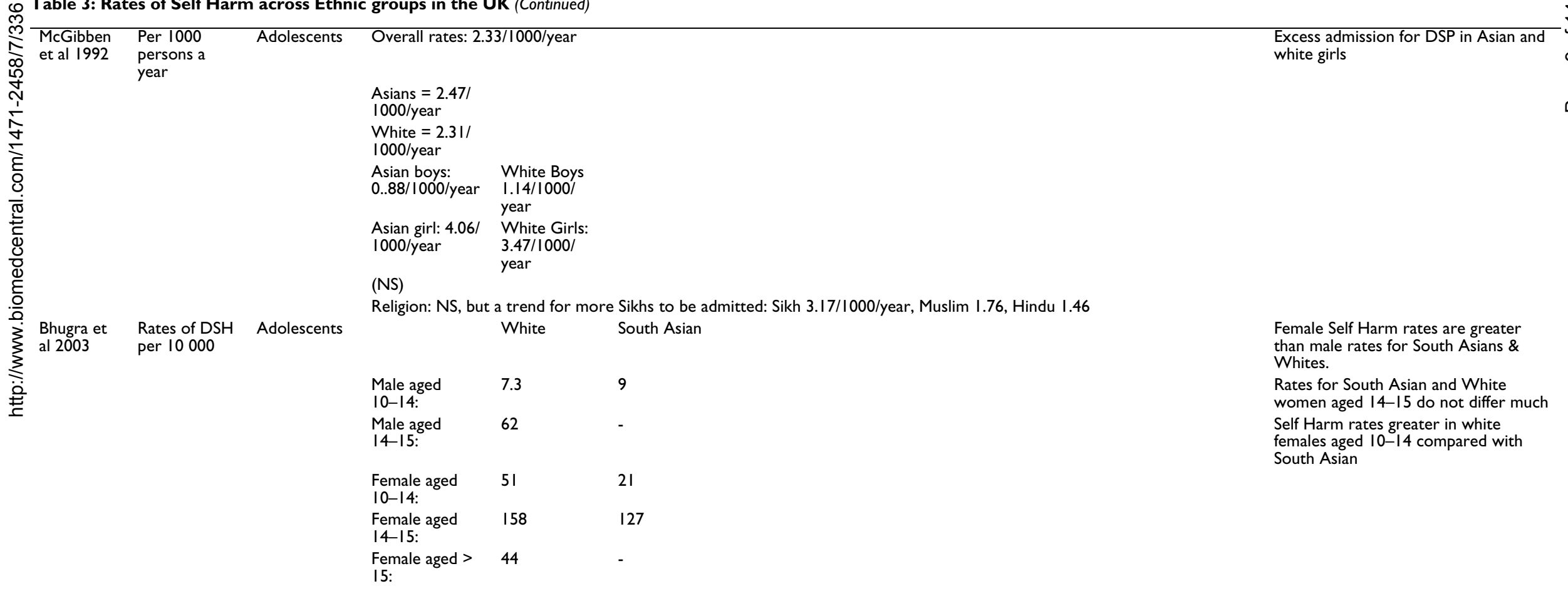


Some studies took care to ascribe ethnic group using self or observer assigned census categories $[13,17,27]$, whereas others based it upon place of birth $[12,30,32,33]$. Ethnicity was more variously defined in studies using data from medical records and for some studies ethnicity was based on South Asian names [16], place of birth $[14,15,18]$, or country of origin $[21,22]$. In some of these studies it was unclear how ethnicity was defined $[19,20,34]$. Some studies used black to indicate a number of ethnic groups, for example, two publications defined black as being "West Indian, African, Asian or Cypriot" origin $[14,15]$. Furthermore, Bagley and Greer classified people with diverse background from the "coloured commonwealth areas of the Caribbean, Africa, India, Pakistan and Cyprus" as "black" [26].

\section{Adult Studies \\ Clinical Characteristics and Risk Factors \\ Repeated attempts}

The majority of studies reported lower rates of repeat self harm in South Asian and Caribbean origin groups. Previous histories of self harm were less common amongst West Indians and South Asians presenting with self harm $[12,14,22,27,32]$. Bagley et al showed that "Black" people (representing a mixed group of BME groups) were more likely to make a repeat suicide attempt, compared with a White comparison group, if they had not received psychiatric treatment or social care following a self-harm episode [26].

\section{Impulsivity}

Two studies concluded that interpersonal disputes precipitated the self harm more frequently among immigrant than white patients, and suggested that situational stress more frequently led to impulsive acts of self harm among the black group $[12,26,32]$. This suggested an absence of ongoing psychiatric illness, but also that self harm emerged in response to interpersonal distress. South Asian women who self harmed were more likely to express regret than a control group; this again suggests that impulsive acts were more common amongst South Asians [31].

\section{Psychiatric Disorder}

In most studies psychiatric disorders were assessed using clinical diagnoses rather than standardised or validated assessment scales. Evidence of differences in the rates of psychiatric disorder in self harming patients among different ethnic minority groups is not consistent. No one in a South Asian sample of burns victims had a history of psychiatric disorder [34]. No psychiatric diagnoses were found in $77 \%$ of White and South Asian presenters to emergency departments [28]. Bhugra et al reported depression was less common among South Asian self harmers compared with their White British counterparts [31]. Merrill \& Owens found that West Indians had a lower risk of psychiatric illness when compared with White British subjects [15]. Conversely, Merrill \& Owens reported that psychiatric illness was less common among whites when compared with South Asian subjects [14]. Burke et al's early studies found psychiatric disorders among a third of South Asian presenters and depression among 20 of 22 West Indians admitted following self poisoning [12,32]. When investigating a sample of African Caribbean people with psychosis, McKenzie et al reported a lower risk of self harm over a two year follow up period [27].

\section{Culture Conflict}

Where social or interpersonal distress was related to culturally specific practices, expectations or beliefs, research studies often concluded that 'cultural conflict' was present. Bhugra et al compared a variety of socio-cultural risk factors for self harm in South Asian and White patients [31]. In this case-control study, Asian women who were suicide attempters were matched on age and sex with Asian controls. Suicide attempters were more likely to have less traditional cultural attitudes, to report recent family arguments and to be in a cross-racial relationship with a white person [31]. Only 30\% of the suicide attempters reported that arranged marriages were a good idea, while $80 \%$ of the control group held these views. Unfavourable attitudes towards arranged marriage seemed to be associated with self harm, and may reflect adverse experiences of arranged marriage which generated mental distress when faced with an arranged marriage, or less traditional attitudes leading to conflict with people in the person's cultural reference group, with or without a personal experience of arranged marriage. Merrill \& Owens concluded that culture conflict was more common amongst South Asian patients, particularly unmarried females [14]. In a study of self poisoning cultural problems were also reported more often in South Asians than whites [22]. There was no endorsement of questions about culture conflict in the white or West Indian group. In contrast, $28 \%$ of the Asian group reported that cultural problems were the precipitating cause.

\section{Ethnic density}

This refers to the concentration of specific or all ethnic groups in any one geographical area, reflecting the extent to which ethnic minorities may be living in an area where other ethnic minorities live [35]. Rates of self harm in ethnic minorities increased with greater ethnic density and after peaking it decreased with further increases in ethnic density [35].

\section{Methods of Self Harm}

A number of studies compared methods of self harm in different ethnic groups $[16,17,20,22,31,34,36,37]$. Most of these studies collected data on methods of self harm 
from medical records and interviews with patients seen in hospital departments. These described the types of ingested medication, and that oral ingestion of tablets was a common method of self harm. However, there were only a few significant findings. Domestic substances, such as bleach, coal gas and medications, were used more often by South Asians than other ethnic groups; among West Indians psychotropic medications were as commonly used as analgesics [12,32]. However, two studies concluded that attempted suicide by self poisoning was less prevalent in West Indian immigrants than white patients $[12,32]$. Sheth et al reported a specific method for South Asian women admitted to a burns unit; over $70 \%$ of patients admitted to a burns unit following a suicide attempt were South Asian women who had used paraffin to set fire to themselves [34].

\section{Rates of Self Harm}

Two studies reported that South Asian and West Indian men and women had lower rates of self harm when compared with the local general population $[12,32]$. Burke, in a series of studies, showed that admission rates were lower for attempted suicide in immigrants from Commonwealth countries compared with the local Birmingham population $[12,32,33]$. Nonetheless, there were rate differences by age and gender. Rates were highest in older male immigrants (aged 25 and over) and younger female immigrants (aged under 25).

Subsequent studies have demonstrated high rates of self harm among South Asian and some Caribbean groups $[14,15,30,32,35-37]$, and specifically an 8 fold higher risk among UK born Indian females [28]. Rates of attempted suicide were highest in South Asian women in West London when compared with other ethnic groups living in the same area [17]. These trends were most evident in women aged between 16 and 24. Merrill and Owens also showed a higher rate of self poisoning among South Asian women compared with White UK born women [14]. In a later paper, this research group reported that the rates of self-harm were higher in Caribbean born females aged less than 35 compared with White people born in the UK, in the same age group and admitted to the same poisons units [15]. However, this finding did not show statistically significant differences between the ethnic groups when distinct age bands were compared.

McKenzie et al did show age differences in risk of attempted suicide in Caribbean origin patients given a diagnosis of a psychotic illness [27]. Those under 35 were four times more likely to attempt suicide than those over 35.

Only data from two studies could be included in metaanalysis; these studies compared rates of self-poisoning and attempted suicide among Asian and White people presenting to services $[14,17]$. We compared pooled data for men and women separately using a random effects model. Asian women were more likely to self harm compared to White women (pooled Relative Risk 1.4, 95\%CI: 1.1 to $1.8, \mathrm{p}=0.005)$. Asian men were less likely to self harm compared with White men (Relative Risk 0.5, 95\% CI: 0.4 to $0.7, \mathrm{p}<0.001$ ).

\section{Adolescent Studies}

Clinical Characteristics and Risk Factors

Disciplinary issues or arguments with parents were common precipitating factors $[18,24,38]$, with higher rates of parental conflict reported by White males compared with South Asian males [16]. One study noted that disciplinary crises were common in both South Asian and White self harming adolescents, but that among South Asians this revolved around cultural issues [18]. Cultural conflict was associated with poisoning in 17 of 19 South Asian participants [18]; Biswas et al also noted culture conflict as a reason for self-harm in South Asian females rather than males [16]. Problems with parents, schoolwork, and boy or girl friends were more common amongst White adolescents, and problems with siblings were more common among South Asian adolescents [21].

There were few studies of discrimination. Goddard et al concluded that persecution, discrimination and migration related problems were more common among Black compared with White adolescents, especially in males [23]. Few studies examined service use, but in two studies, no ethnic differences were reported in follow-up or service usage $[18,23,24]$. Bhugra et al reported that South Asian adolescents who self harmed mostly did so impulsively and without planning [24]. In contrast Kingsbury et al, in a small study of adolescents, found longer premeditation times among South Asian compared with White adolescents [21].

\section{Methods of Self Harm}

Self-poisoning was the most common method reported among adolescents for all ethnic groups. Analgesics were the most commonly used substance $[21,24,38]$. However, Biswas et al noted that South Asian female adolescents were more likely to use "non-ingestants" (e.g household disinfectant, mouse poisons) than White adolescent girls [16]. In contrast, Handy et al's study of adolescent selfpoisonings showed that there was little difference in the type of self-poisoning method used by young White and South Asian adolescent [18].

\section{Comparative Rates}

McGibben et al showed that although the rates for self poisoning for South Asian and White female adolescents did not differ significantly, both South Asian and White 
females were significantly more likely to be admitted for self poisoning than boys [13]. Only amongst females aged 10-14 were the rates of self harm higher among White compared with South Asian subjects [24]. The only school based study reported a lower risk of self harm among South Asian girls in the unadjusted analyses, but this finding was not sustained in multivariate analyses [19].

\section{Discussion \\ Methodological Issues}

Most studies could not be subjected to meta-analyses due to distinct outcomes, samples and methods; specifically methods of ethnic classification varied and changed over time making time trends difficult to discern. Only two studies could be pooled [14,17] offering further support for there being a higher risk of self harm among South Asian women. The inability to undertake meta-analyses on a larger number of studies reflected that publications did not include information on numerators and denominators, and census data were not always available for the study periods of interest or the age and gender group, for the local geographical areas in which the studies were conducted.

There is little good quality data comparing self harm in different ethnic minority groups in the UK. Most of the studies have significant methodological limitations, perhaps because these were the first to investigate self harm and ethnicity. Few explicitly presented numerator and denominator data, or used validated measures of mental disorder and deliberate self harm. Sample sizes were often small, and some studies did not set out to assess ethnic differences but reported these. Most of the studies used clinical samples rather than community samples, and none followed pathways into care. There were only two national studies; one investigated adult admissions for self poisoning in England, Scotland and Wales [25]; the other was a self report school based study of adolescents [19]. Differences in the findings across the studies may reflect variation of access to services as well as actual differences in rates and risk factors between ethnic minority populations.

\section{Demographic \& Cultural Risks}

The available evidence suggests that women of South Asian origin are over-represented in self harming samples compared to white women and men. There is some evidence that those of South Asian origin and aged under 35 are at higher risk than those over 35 . There is also evidence of increasing risk in those of Caribbean origin aged less than 35 years $[27,36]$. However, there were few studies among adolescents, and the findings are inconsistent; one study showed a higher risk [24] and one a lower risk [19] of self harm among South Asian girls.
The most common method of self harm was self poisoning with analgesics or psychotropics. Previous histories of repeated self harm were reported less often in South Asian and Caribbean adults. South Asian and Caribbean origin people appeared to be less likely to show previous episodes of self harm, were less likely to have mental disorder in some studies, and were more likely to self harm impulsively. These findings will need to be considered by practitioners when assessing South Asian and Caribbean people for risk of self harm.

There have been some attempts to investigate possible reasons for different rates of self harm across ethnic groups. However, the results of these studies are not always consistent for South Asian and Caribbean origin people. Studies that report "culture conflict" in order to explain differential rates of suicide in South Asian and white groups are difficult to interpret. It was not always clear what was meant by culture conflict in the White group, and some attributions of culture conflict appeared to label social and interpersonal conflicts where these were judged by authors to be of cultural origin. There was rarely a validated instrument to assess cultural genesis of distress, for example, due to strain of gender roles, or of religious roles. It is unlikely that the questions asked to Asians about cultural practices, for example arranged marriages, would have had much significance or meaning in the white group, this perhaps explaining the low endorsement rates for these questions ( $0 \%$ and $1.8 \%)$.

One study demonstrated a link between ethnic minority density of population and risk of self harm [35]. Because explanatory factors such as social support and racism were not collected it is not clear what exactly is mediating the relationship between ethnic density and self harm rates. As only $50 \%$ of people who self harm come into contact with services, it is not clear whether the rates of self harm themselves are increased or whether the rates of presentation to services can explain some of the reported ethnic variations.

\section{Future Research}

Better definition of ethnic groups is essential, especially for comparisons over time and internationally. Population studies following individuals into help seeking, from conventional and non-conventional sources of help may unravel the most appropriate care pathways for prevention among diverse ethnic groups. Of note there were no reports of self harm in refugee and asylum seekers or prison populations. Follow up studies using validated measures of mental distress and self harm are necessary for better prediction of risk for different ethnic groups. Population based studies that follow individuals through their care pathways are necessary in order to fully discern whether culturally determined patterns of help seeking or 
whether limited access to services account for the ethnic variations of rates in services. New patterns of immigration from Europe and the influence of globalisation on cultural practices also challenge conventional paradigms of researching ethnic inequalities.

\section{Conclusion}

This review finds some ethnic differences in the nature and presentation of self harm. For example, compared to their white counterparts, Asian women were more likely to self harm and Asian men were less likely to self harm. The overall findings argue for ethnic specific preventive actions. However, the literature does not comprehensively cover the UK's diverse ethnic groups. Future prospective studies will need to consider new ethnicities.

\section{Competing interests}

The author(s) declare that they have no competing interests.

\section{Authors' contributions}

$\mathrm{KB}$ was the grant holder, KM was a co-PI and FR the research assistant employed on the grant. FR undertook searches and followed the methodology devised by KB and $\mathrm{KM}$ and strengthened in conjunction with the steering group. The manuscript was drafted first by FR, and then finalised by KB with comments on consecutive drafts by KM. All three authors took part in the analysis and tabulation of the data.

\section{Additional material}

\section{Additional file 1}

additional file $\%$. Clinical Risk Factors \& Methods for Self Harm in Ethnic Groups in the UK.

Click here for file

[http://www.biomedcentral.com/content/supplementary/1471-

2458-7-336-S1.doc]

\section{Acknowledgements}

The review was funded as part of the National Institute for Mental HealthEngland's programme on Black and Minority Ethnic Mental Health, and as an action under the National Suicide Prevention Strategy. Thanks to David Gunnell, the steering group, and Keith Hawton for advice and comments on earlier drafts,

\section{References}

I. Kerkhof AJFM, Arensman E: Attempted suicide and deliberate self harm: epidemiology and risk factors. Volume $I$. Edited by: Gelder MGLopez-lbor J, Andreasan NC. New Oxford Textbook of Psychiatry; 2000:1039-1045.

2. Owens D, Horrocks J, House A: Fatal and non-fatal repetition of self-harm. Systematic review. Br J Psychiatry 2002, I 8 I: I93-9.

3. Cooper J, Kapur N, Webb R, Lawlor M, Guthrie E, Mackway-Jones K, Appleby L: Suicide after deliberate self-harm: a 4-year cohort study. Am J Psychiatry 2005, I 62(2):297-303.
4. Kapur N, Cooper J, Rodway C, Kelly J, Guthrie E, Mackway-Jones K: Predicting the risk of repetition after self harm: cohort study. BMJ 2005, I9;330(7488):394-5.

5. Bhui K, Stansfeld SA, Hull S, Priebe S, Mole F, Feder G: Ethnic variations in pathways to and use of specialist mental health services in the UK. British Journal of Psychiatry 2003, I 82:105-I I6.

6. DH: National Suicide Prevention Strategy. Department of Health. 2002 [http://www.dh.gov.uk/assetRoot/04/01/95/48/ 04019548.pdf].

7. DH: Delivering Race Equality. 2003 [http://www.dh.gov.uk/asset Root/04/10/07/75/04100775.pdf].

8. O'Donnell L, O'Donnell C, Wardlaw DM, Stueve A: Risk and resiliency factors influencing suicidality among urban African American and Latino youth. American Journal of Community Psychology 2004, 33( I 2):37-49.

9. Chen PC, Lee LK, Wong KC, Kaur J: Factors relating to adolescent suicidal behaviour: a cross-sectional Malaysian school survey. J Adolesc Health 2005, 37(4):337-.

10. Evans E, Hawton K, Rodham K, Deeks J: The prevalence of suicidal phenomena in adolescents: a systematic review of population-based studies. Suicide Life Threat Behav 2005, 35(3):239-50.

II. NELMH: Suicide and Minority Ethnic People. 2005 [http:www.library.nhs.uk/ethnicity/ViewRe source.aspx?resID=| | |332\&tabID=290].

12. Burke AW: Socio-cultural determinants of attempted suicide among West Indians in Birmingham: ethnic origin and immigrant status. British Journal of Psychiatry 1976, I 29:26 I-6.

I3. McGibben L, Ballard CG, Handy S, Mohan RNC, Silveria WR: Deliberate self poisoning in Asian \& Caucasian I2-I5 year olds. British Journal of Psychiatry 1992, I6 I: I I 0-1 I 2.

14. Merrill J, Owens J: Ethnic differences in self-poisoning A comparison of Asian and white groups. British Journal of Psychiatry 1986, |48:708-7|2.

15. Merrill J, Owens J: Ethnic differences in self-poisoning A comparison of West Indian and white groups. British Journal of Psychiatry 1987, I 50:765-768.

16. Biswas S: Ethnic differences in self-poisoning: A comparative study between an Asian and White adolescent group. Journal of Adolescence 1990, I 3:189-93.

17. Bhugra D, Desai M, Baldwin DS: Attempted suicide in West London I. Rates across ethnic communities. Psychological Medicine 1999, 29: I I 25- II30.

18. Handy S, Chithiramohan RN, Ballard CG, Solveira WR: Ethnic differences in adolescent self-poisoning: a comparison of Asian and Caucasian groups. Journal of Adolescence I991, I 4:I57-62.

19. Hawton K, Rodham K, Evans E, Weatherall R: Deliberate self harm in adolescents: self report survey in schools in England. BMJ 2002, 325: | 207- I2II.

20. Lockhart SP, Baron JH: Changing ethnic and social characteristics of patients admitted for self-poisoning in West London during $1971 / 2$ and 1983/4. Journal of the Royal Society of Medicine 1987, 80:145-8.

21. Kingsbury S: The psychological and social characteristics of Asian adolescent overdose. Journal of Adolescence 1994, 17:131-135.

22. Wright N, Trethowan WN, Owens J: Ethnic differences in selfpoisoning. Postgraduate Medical Journal I98I, 57:792-3.

23. Goddard N, Subotsky F, Fombonne E: Ethnicity and adolescent self-harm. Journal of Adolescence 1996, 19:513-521.

24. Bhugra D, Thompson N, Singh J, Fellow-Smith E: Inception rates of DSH among adolescents in West London. International Journal of Social Psychiatry 2003, 49:247-250.

25. Dean G, Adelstein A, Spooner J: Suicide in and self-poisoning in Great Britain and Ireland. International Journal of Epidemiology 1976, 5:|45-|5|.

26. Bagley C, Greer S: Black suicide: A report of $\mathbf{2 5}$ English cases and controls. Journal of Social Psychology 1972, 86: I75-I79.

27. McKenzie K, van Os J, Samele C, van Horn E, Tattan T, Murray R, on behalf of the UK700 group: Suicide and attempted suicide among people of Caribbean origin with psychosis living in the UK. British Journal of Psychiatry 2003, I 83:40-44.

28. Neeleman J, Jones P, Van Os J, Murray RM: Parasuicide in Camberwell-ethnic differences. Soc Psychiatry Psychiatr Epidemiol 1996, 3 I (5):284-287. 
29. McKenzie K, van Os J, Fahy T, Jones P, Harvey I, Toone B, Murray R: Psychosis with good prognosis in Afro-Caribbean people now living in the United Kingdom. BMJ 1995, 3 I I(70 I6): I325-I328.

30. Merrill J, Owens J: Self-poisoning among four immigrant groups. Acta Psychiatrica Scandinavica 1988, 77:77-80.

31. Bhugra D, Baldwin DS, Desai M, Jacob KS: Attempted suicide in West London, II. Inter-group comparisons. Psychological Medicine 1999, 29: I|3|-II39.

32. Burke AW: Attempted suicide among Asian immigrants in Birmingham. British Journal of Psychiatry 1976, 128:528-33.

33. Burke AW: Classification of attempted suicide from hospital admission data. Int J Soc Psychiatry 1976, 26(I):27-34.

34. Sheth H, Dziewulski P, Settle JAD: Self-inflicted burns; a common way of suicide in the Asian population. A ten-year retrospective study. Burns 1994, 20(4):334-5.

35. Neeleman J, Wilson-Jones C, Wessley S: Ethnic density and deliberate self-harm; a small area study in South East London. Journal of Epidemiology and Community Health 200I, 55:85-90.

36. Soni-Raleigh V: Suicide patterns and trends in people in Indian Subcontinent and Caribbean origin in England \& Wales. Ethnicity \& Health 1996, 1:55-63.

37. Neeleman J, Wessley S: Ethnic minority suicide: a small area geographical study in south London. Psychological Medicine 1999, 29:429-436.

38. Bhugra D, Thompson N, Singh J, Fellow-Smith E: Deliberate self harm in adolescents in West London: Socio-cultural factors. European Journal of Psychiatry 2004, 18:91-98.

\section{Pre-publication history}

The pre-publication history for this paper can be accessed here:

http://www.biomedcentral.com/1471-2458/7/336/pre

pub

Publish with Biomed Central and every scientist can read your work free of charge

"BioMed Central will be the most significant development for disseminating the results of biomedical research in our lifetime. "

Sir Paul Nurse, Cancer Research UK

Your research papers will be:

- available free of charge to the entire biomedical community

- peer reviewed and published immediately upon acceptance

- cited in PubMed and archived on PubMed Central

- yours - you keep the copyright

Submit your manuscript here:

http://www.biomedcentral.com/info/publishing_adv.asp
BioMedcentral 